\title{
Sala polivalente del Liceo Francés de Valencia
}

Orts - Trullenque arquitectos

Recibido 2017.12.04 ::. Aceptado 2017.12.06 DOI: 10.5821/palimpsesto.17.5380

\begin{abstract}
A nivel urbanístico, la construcción de la nueva Sala Polivalente supone agotar los últimos metros ocupables de la parcela. Por otro lado, la edificabilidad a la que dicha ocupación daba derecho casi duplicaba las necesidades planteadas por el concurso.
\end{abstract}

\section{Decidimos agotar la edificabilidad permitida con el fin de} ofrecer un edificio que, como una infraestructura capaz, pudiera albergar los usos requeridos, pero también resolver carencias funcionales del Colegio y acoger usos futuros y a la vista necesarios como: espacios de instalaciones, talleres y almacenes de mantenimiento del Centro y nuevas aulas. A su vez, la propia actividad del Colegio invitaba igualmente a pensar en aumentar el aforo de la sala, así como la capacidad de los espacios pre-escena y post-escena.

A cambio, había que encontrar y justificar las soluciones que hicieran viable esta estrategia a nivel económico: construir de manera simple, tanto formal como

técnicamente, dejar por acondicionar los espacios "extra" propuestos, establecer prioridades, ofrecer posibilidades progresivas de mejora en cuanto a costes y en el tiempo y, finalmente, utilizar pocos materiales, fáciles y baratos.

El entorno construido de la Sala Polivalente tiene un fuerte carácter formal que está presente en la memoria de quienes lo conocen o lo han vivido: tres edificios cilíndricos (les "tambours") ocupan esa parte de la parcela albergando las clases de los pequeños y el comedor. E edificio asume la forma de sus vecinos para insertarse con educación en el sitio, como lo haría un árbol en un bosque: es un juego de iguales y diferentes.

El nuevo cilindro se implanta resolviendo los problemas de articulación que tenían los espacios intersticiales entre los tambores existentes: unos espacios potencialmente fluidos y divertidos, pero hasta ahora acotados por cercados y barreras. Por otro lado, gracias a la topografía de la parcela, un paso semienterrado para carga y descarga soluciona definitivamente el cruce de los usuarios con los vehículos de servicio.

Tipológicamente la sala circular no resulta evidente. Su condición polivalente incita a que sea abstracta y posibilista y sus siete lucernarios cilíndricos aseguran la luz natural cuando se necesita, acaparando la atención luz natural cuando se necesita, acaparando la atención
de los niños. Las operaciones radiales y perimetrales resuelven accesos y recorridos prolongando la percepción espacial de la sala y la experiencia del usuario a través de ella: se trata de un espacio que no quiere renunciar a tener su propio carácter, a conformar una atmósfera que permanezca en el recuerdo de sus usuarios.
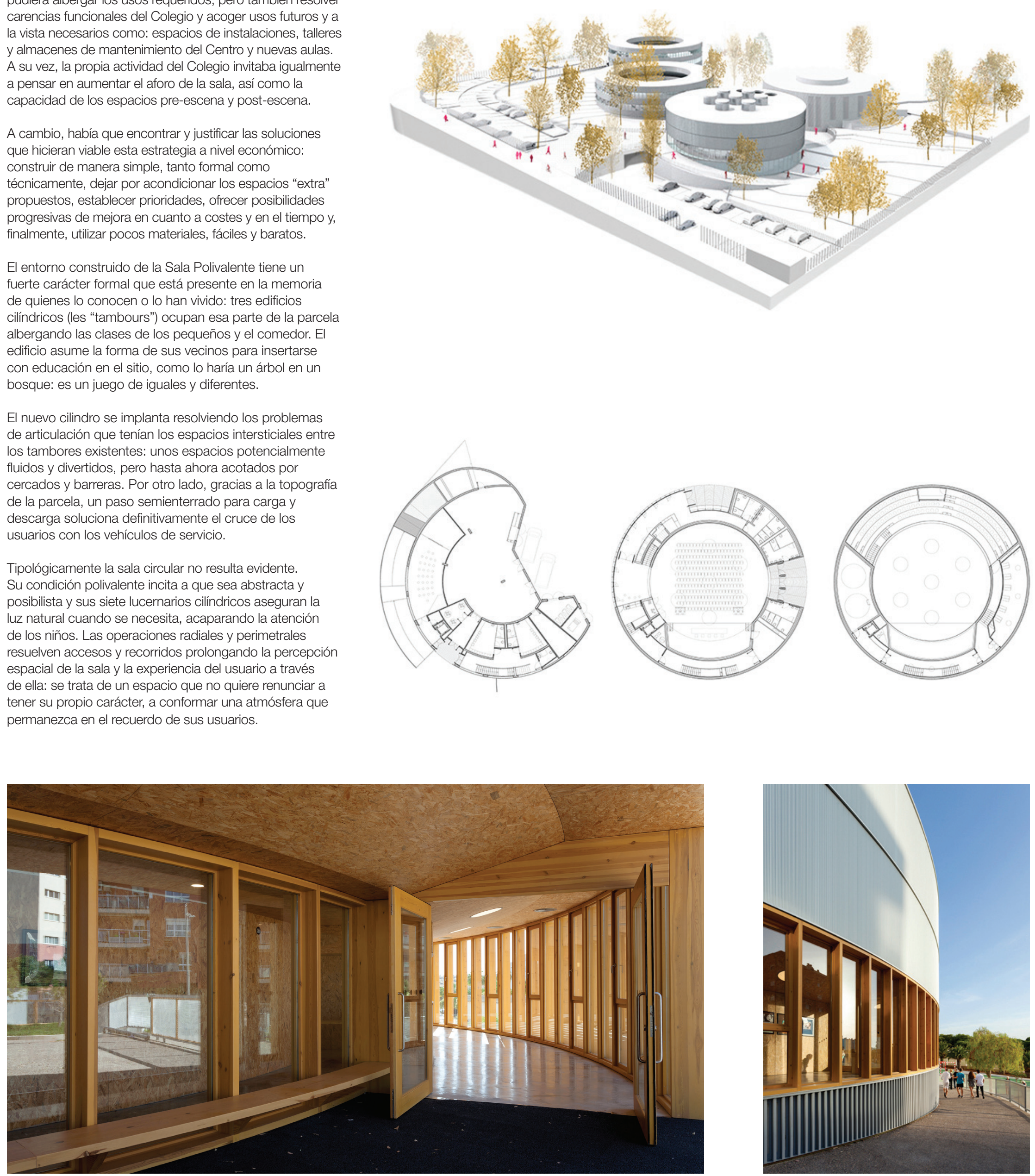


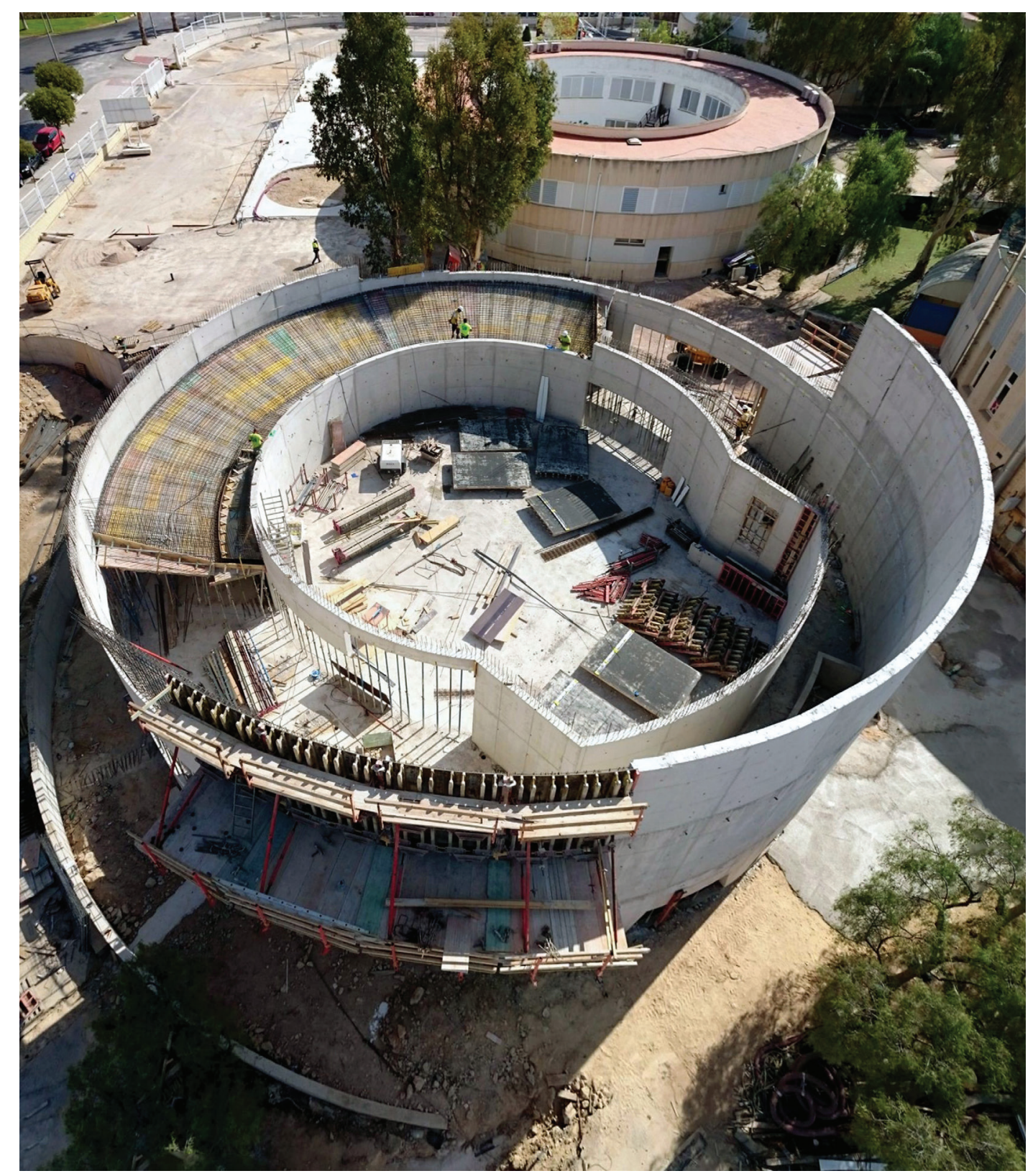

La estructura de hormigón armado, a la vez portante y paramento, es extremadamente eficaz: de nuevo, gracias a la forma, se logra casi sin sin esfuerzo una luz, en voladizo, de hasta $35 \mathrm{~m}$ en el vestíbulo de acceso. Sin embargo, se renuncia de manera consciente a hacer exhibición de ello, más bien se asume con naturalidad los eficaces forros térmicos exteriores.

La propuesta prolonga su estrategia de

inserción hasta convertirla en una estrategia arquitectónica en sí misma, que se traduce en excelentes resultados energéticos (63 $\left.\mathrm{kWh} / \mathrm{m}^{2} a n ̃ o\right)$ y presupuestarios (1,4 M€ de PEC: $\left.750 € / \mathrm{m}^{2}\right)$ gracias, fundamentalmente, al factor de forma del nuevo edificio.

Los revestimientos empleados son de

procedencia industrial: maderas recicladas (OSB), chapas perfiladas o extruidas, hormigones y pinturas. El resto consiste en poner árboles, muchos árboles.

NOTA: a fecha de hoy, apenas seis meses después de finalizar la obra, todos los espacios extra propuestos ya han sido utilizados.

Promotor: AEFE (Agence pour

l'enseignement Français á l'Étranger) LFV (Lycée Français de Valencia)

Arquitectos: orts-trullenque arquitectos Arquitectos Directores: Marta Orts - Carlos Trullenque

Arquitectos Colaboradores: Ana Villalba, Magdalena Domoslawska, Javier García, Jesús Santamans, Alejandra Ruano

Estructura: Estructuras Singulares (David Gallardo, arquitecto)

Medioambiente: Societat Orgànica

Acústica: Grupo de Acústica Arquitectónica UPV

Arquitecto técnico: Rafael Duet

instalaciones: Consulting de ingeniería ICA

Infografías de concurso: Estudio Agraph

Fotografías de la obra: Diego Opazo
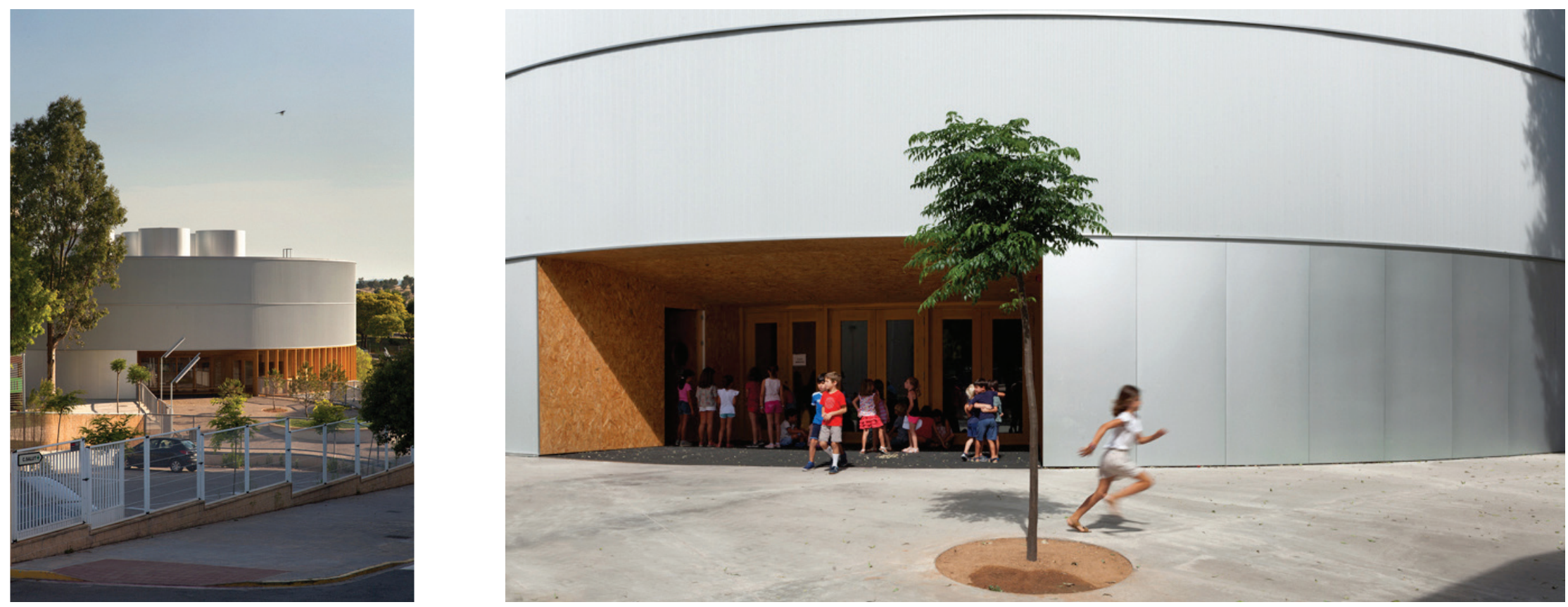